Doi: $10.32481 /$ djph.2021.12.016

\title{
Characteristics and Outcomes of SARS-CoV-2 Infection Among Adults Living With HIV In Delaware:
}

\section{The Story of a Syndemic During the First 12 Months of the SARS-CoV-2 Pandemic}

Adam K Skrzynski, MD ${ }^{1}$ Brooke L Darmstadter, PharmD, AAHIVP; ${ }^{1}$ Sharon P Miner, AGPCNP-BC; ${ }^{1}$ Keshab Subedi, MS, MSc ${ }^{2}$ Deborah Kahal, MD, MPH, FACP ${ }^{1}$

1. ChristianaCare, William J. Holloway Community Program

2. ChristianaCare, Value Institute

\begin{abstract}
Objective: To better characterize the intersection of the HIV and SARS-CoV-2 pandemics, including our robust statewide panel of people living with HIV, in the State of Delaware.
\end{abstract}

Methods: We conducted a retrospective descriptive case-series that identified people living with HIV $\geq 18$ years old co-infected with SARS-CoV-2 from 1 March 2020 through 9 March 2021 who attended our ambulatory HIV program, through review of testing results, electronic medical records and external clinical records. Results: There were 105 confirmed cases of SARS-CoV-2 infection and 4 attributable deaths from COVID-19 among adult people living with HIV from 1 March 2020 through 9 March 2021. Co-infected patients had very high rates of ART prescription and virologic suppression, with robust CD4 counts. 24/105 (22.9\%) SARS-CoV-2 cases were hospitalized due to COVID-19 and had a significant burden of co-morbidities; a vast majority were AIDS-defined. Age, BMI $>30 \mathrm{~kg} / \mathrm{m}^{2}$, cardiovascular disease, chronic kidney disease and cirrhosis were independently associated with hospitalization by logistic regression. Black patients appeared to have lower rates of testing and higher rates of hospitalization. Additionally, those with history of natural immunity to hepatitis B virus exhibited a low rate of hospitalization. Conclusions: Our cohort data is the first to capture the experience of patients co-infected with HIV/SARS-CoV-2 in Delaware, demonstrating the risk of long-term immunosuppression and burden of comorbid disease, even in the setting of virologic suppression. Although not reaching statistical significance, we identified high rates of resolved hepatitis B virus infection amongst non-hospitalized co-infected patients and postulate there may be an underlying immunologic mechanism to this hypothesis-generating observation. Our results also highlight the role that healthcare disparities have played during these overlapping pandemics. Policy Implications: Pronounced healthcare disparities are known to worsen outcomes in a variety of disease states. From our descriptive data, we suggest continued efforts to address the social determinants of health, especially as they pertain to common chronic comorbid conditions and certain Black communities.

\section{Background}

The intersection of the human immunodeficiency virus (HIV) and severe acute respiratory syndrome coronavirus-2 (SARS-CoV-2) pandemics has opened a Pandora's box of unanswered questions within medicine. As of this writing, SARS-CoV-2 has infected 210 million individuals worldwide, including many people living with HIV (PLWH), of whom there are estimated to be 37.9 million individuals at present. Due to the immunosuppressive and inflammatory effects of HIV, concern has emerged over the possibility of worse outcomes in PLWH affected by 
COVID-19. Worldwide studies have yielded variable associations between HIV and increased risk of morbidity and mortality from SARS-CoV-2/HIV co-infection when compared to people without HIV infection. ${ }^{1-12}$ Delaware has been severely affected by overlapping HIV and SARSCoV-2 pandemics, including our robust statewide panel of PLWH. We hope to better characterize this intersection amongst PLWH in Delaware as captured through the first year of the SARS-CoV-2 pandemic.

Of great concern, the COVID-19 pandemic has disproportionately and more severely affected communities of color and lower socioeconomic status, both in the United States $6,9,10,12-15$ and abroad. ${ }^{2,16,17}$ In similar fashion to non-HIV infected individuals, PLWH with COVID-19 tend to have at least one high-risk co-morbidity associated with severe disease, ${ }^{5,15,18}$ including older age, ${ }^{1,17-20}$ male sex ${ }^{1,6,17}$ diabetes mellitus type $2(\mathrm{DM}),{ }^{1,6,10,14,17,21}$ hypertension (HTN), ${ }^{1,6,10,14,15,17,19,21}$ hyperlipidemia (HLD),${ }^{14}$ chronic lung disease (CLD),${ }^{6,9,10,19,21}$ chronic kidney disease (CKD), ${ }^{6,17}$ obesity, ${ }^{4,6,10,15}$ cardiovascular disease (CVD), ${ }^{6,15}$ tobacco use, ${ }^{6,10,11}$ and chronic liver disease. ${ }^{4}$ It is the hope that PLWH, who are adherent to an effective anti-retroviral treatment (ART) regimen with adequate CD4+ cell count and virologic suppression, incur no excess morbidity or mortality beyond that imposed by their other comorbid conditions and demographic risk factors. However, the evidence is not yet definitive in either direction. Here, we present a cohort of co-infected patients from the ChristianaCare William J. Holloway Community Program, located at multiple sites in Delaware, with a hope to shed more light on this question.

\section{Study Population, Setting and Design}

The William J. Holloway Community Program serves as the sole Ryan White-funded HIV clinical program in Delaware. The program cares for 1754 of the state's 3050 HIV-infected individuals currently accessing care (57.5\%), at six clinical sites: three sites in New Castle County (with the largest at the Wilmington Hospital campus), two in Kent County and one in Sussex County. Patients from all clinical sites were eligible for study inclusion. This retrospective descriptive case-series identified PLWH $\geq 18$ years old co-infected with SARSCoV-2 from 1 March 2020 through 9 March 2021 who attended any of our ambulatory HIV programs. Infections were confirmed by documentation of positive SARS-CoV-2 nasopharyngeal polymerase chain reaction (PCR) or reactive SARS-CoV-2 IgG antibody testing following compatible clinical presentation for COVID-19. Patients were identified during the study period through review of individual testing results, the ChristianaCare electronic medical record (EMR) and external inpatient and/or outpatient clinical records. The William J. Holloway Program is electronically notified in real-time whenever a program-participating patient presents to a ChristianaCare-affiliated emergency department or is hospitalized within the ChristianaCare health system. Patients with self-reported SARS-CoV-2 required confirmation of definitive infection by way of review of all available EMR and external data. Patients for whom SARSCoV-2 infection could not be laboratory confirmed were excluded from the study, including presumptive or probable COVID-19 cases. The study received ChristianaCare Internal Review Board approval. Utilizing The R Project for Statistical Computing online software environment, Chi-Square and t-tests compared categorical and continuous variables respectively between hospitalized and non-hospitalized patients; logistic regression modeling evaluated co-variates associated with hospitalization. 


\section{Data Collection and Analysis}

Pre-defined individual data categories were collected in secure fashion with removal of all personal identifiers. All chart review and data extraction were completed by two study authors with the a priori development of all study definitions and terms. To characterize patients coinfected with HIV/SARS-CoV-2, we collected demographic data, clinical data related to HIV diagnosis, relevant medical history including co-morbidities, and medication history including ART, as well as data pertaining to SARS-CoV-2 diagnosis and management. Data of all PLWH attending the William J Holloway Program was extracted through pre-existing 2020 HIV CareWare data.

Descriptive data analysis was performed on this case series. Data regarding the general HIV clinic population is provided for context; however, a case-control study was not undertaken.

Mean values were calculated for non-skewed variables. Attempts were made to uniformly calculate and present measures of patients co-infected with HIV/SARS-CoV-2 and those requiring hospitalization across multiple tables.

\section{Results}

There were 105 cases of SARS-CoV-2/HIV co-infection with 24 (22.9\%) hospitalizations (with nine of these patients requiring ICU-level care) and four attributable deaths due to COVID-19 among our program's adult PLWH from 1 March 2020 through 9 March 2021. One hundred four (104) cases were identified through positive SARS-CoV-2 nasopharyngeal PCR testing. One case was identified in a patient with a compatible clinical syndrome followed by positive SARSCoV-2 IgG antibody testing three months after resolution of symptoms. Baseline demographic and HIV characteristics of adults co-infected with HIV/SARS-CoV-2 are presented in Table 1. Overall, the cohort had high rates of ART utilization (95.2\%, on predominantly INSTI-based regimens with TAF-based NRTI backbone), virologic suppression $(89.4 \%$ with viral load $<200$ cells $/ \mathrm{mL}$ ) and robust CD4 counts (mean 549 cells $/ \mathrm{m}^{3}$ ) preceding SARS-CoV-2 co-infection. Sixty-seven percent of co-infected patients were AIDS-defined based on historical nadir CD4 count and/or history of opportunistic infection, and had been living with HIV for a mean of 13 years. Thirty-two percent of all co-infected patients with available data had significant ART resistance.

Table 1. Baseline Characteristics of HIV/SARS-CoV-2 Co-Infected Patients and HIV Program Population

\begin{tabular}{|l|l|}
\hline & $(\mathrm{n})(\%)$ \\
\hline Total & 105 \\
\hline Sex, biologic & \\
\hline Male & $71(67.6)$ \\
\hline Race & \\
\hline Black & $66(62.9)$ \\
\hline White & $26(24.8)$ \\
\hline Hispanic & $10(9.5)$ \\
\hline Other & $3(2.9)$ \\
\hline Mean Age (SD) & $50.2(12.5)$ \\
\hline Age Range & \\
\hline 18-24 years old & $1(1.0)$ \\
\hline
\end{tabular}




\begin{tabular}{|c|c|}
\hline $25-40$ years old & $22(21.0)$ \\
\hline $41-50$ years old & $23(21.9)$ \\
\hline$>60$ years old & $22(21.0)$ \\
\hline \multicolumn{2}{|l|}{ Insurance } \\
\hline None & $3(2.9)$ \\
\hline Private & $41(39.4)$ \\
\hline Public & $60(57.7)$ \\
\hline \multicolumn{2}{|l|}{ ART Class $^{a}$} \\
\hline INSTI & $75(75.0)$ \\
\hline INSTI + NNRTI & $6(6.0)$ \\
\hline INSTI + PI & $6(6.0)$ \\
\hline INSTI + PI + NNRTI & $2(2.0)$ \\
\hline NNRTI & $3(3.0)$ \\
\hline PI & $7(7.0)$ \\
\hline $\mathrm{PI}+\mathrm{EI}^{\mathrm{b}}$ & $1(1.0)$ \\
\hline Mean Years Living with HIV (SD) & $13.3(9.3)$ \\
\hline \multicolumn{2}{|l|}{ HIV Viral Load Range } \\
\hline$<200($ copies $/ \mathrm{mL})$ & $93(89.4)$ \\
\hline $200-1000($ copies $/ \mathrm{mL})$ & $1(1.0)$ \\
\hline$>1000($ copies $/ \mathrm{mL})$ & $4(3.8)$ \\
\hline$>5000($ copies $/ \mathrm{mL})$ & $6(5.8)$ \\
\hline Mean CD4 Count $\left(\right.$ cells $\left./ \mathrm{mm}^{3}\right)(\mathrm{SD})$ & $548.9(257.2)$ \\
\hline CD4 Count $\leq 200$ cells $/ \mathbf{m m}^{3}$ & $10(9.6)$ \\
\hline \multicolumn{2}{|l|}{ CD4 Count Nadir Range (cells/mm³) } \\
\hline$<50$ cells $/ \mathrm{mm}^{3}$ & $20(19.0)$ \\
\hline $51-100$ cells $/ \mathrm{mm}^{3}$ & $11(10.5)$ \\
\hline $101-200$ cells $/ \mathrm{mm}^{3}$ & $18(17.1)$ \\
\hline$>200$ cells $/ \mathrm{mm}^{3}$ & $35(33.3)$ \\
\hline CD4 Count Nadir $\leq 200$ cells $/ \mathbf{m m}^{3}$ & $49(46.7)$ \\
\hline AIDS-Defined & $67(67.0)$ \\
\hline HIV ART Resistance ${ }^{c}$ & $32(38.6)$ \\
\hline \multicolumn{2}{|l|}{ Hepatitis B Infection } \\
\hline Chronic Hepatitis B Infection & $8(7.6)$ \\
\hline Resolved Hepatitis B Infection $^{d}$ & $15(14.3)$ \\
\hline \multicolumn{2}{|l|}{ Hepatitis C Infection } \\
\hline Chronic Hepatitis C Infection & $4(3.8)$ \\
\hline Treatment with Cure & $9(8.6)$ \\
\hline Spontaneous Clearance & $9(8.6)$ \\
\hline \multicolumn{2}{|l|}{ Comorbidities } \\
\hline BMI (mean)(SD) & $31.4(8.1)$ \\
\hline Cardiovascular Disease (\%) & $22(21.0)$ \\
\hline Diabetes (\%) & $21(20.0)$ \\
\hline Hypertension (\%) & $53(50.5)$ \\
\hline Dyslipidemia (\%) & $51(48.6)$ \\
\hline Chronic Kidney Disease (\%) & $16(15.2)$ \\
\hline
\end{tabular}




\begin{tabular}{|l|l|}
\hline Chronic Lung Disease (\%) & $24(22.9)$ \\
\hline Cirrhosis (\%) & $7(6.7)$ \\
\hline Hospitalized & $24(22.9)$ \\
\hline ICU Admission (\%) & $9(13.6)$ \\
\hline
\end{tabular}

Note: $\mathrm{a}=$ in addition to NRTI backbone (F/TAF in vast majority of patients); $\mathrm{b}=$ entry inhibitor, i.e. maraviroc; $\mathrm{c}=$ defined as clinically significant resistance to ART in one or more drug class; $\mathrm{d}$ $=$ either isolated anti-HBc (with negative HBV DNA) or anti-HBc + anti-HBs

Most hospitalized patients were male and Black (Table 2). Hospitalized patients tended to have less virologic suppression as well as lower proximal and nadir CD4 cell counts, in the setting of high levels of ART resistance. Notably, 20/24 (87.0\%) of hospitalized individuals were historically AIDS-defined and had been living with HIV for a mean duration of 15.8 years. Hospitalized versus non-hospitalized co-infected individuals demonstrated statistically significant differences across multiple variables: mean age (59.0 versus 47.6 years), utilization of public insurance $\left(82.6 \%\right.$ versus $50.6 \%$ ), mean CD4 count (444 cells $/ \mathrm{m}^{3}$ versus $579 \mathrm{cells} / \mathrm{m}^{3}$ ), nadir CD4 count $\leq 200$ cells $/ \mathrm{m}^{3}$ (70.8\% versus $\left.39.5 \%\right)$, AIDS-defined status $(87.0 \%$ versus $61.0 \%)$.

Table 2. Historical Immunologic and Virologic Characteristics of HIV/SARS-CoV-2 CoInfected Patients

\begin{tabular}{|l|l|l|l|}
\hline & $\begin{array}{l}\text { Hospitalized } \\
(\mathbf{n})(\mathbf{\%})\end{array}$ & $\begin{array}{l}\text { Not } \\
\text { Hospitalized } \\
(\mathbf{n})(\%)\end{array}$ & p-Value \\
\hline Total (n) & 24 & 81 & \\
\hline Sex, biologic & & & \\
\hline Male & $17(70.8)$ & $54(66.7)$ & 0.893 \\
\hline Race & & & 0.265 \\
\hline Black & $19(79.2)$ & $47(58.0)$ & \\
\hline White & $4(16.7)$ & $22(27.2)$ & \\
\hline Hispanic & $1(4.2)$ & $9(11.1)$ & \\
\hline Other & $0(0.0)$ & $3(3.7)$ & \\
\hline Mean Age (years) (SD) & $\mathbf{5 9 . 0}(\mathbf{1 1 . 3})$ & $\mathbf{4 7 . 6 ( 1 1 . 7 )}$ & $<\mathbf{0 . 0 0 1}$ \\
\hline Age Range & & & $\mathbf{0 . 0 0 6}$ \\
\hline $18-24$ years old & $0(0.0)$ & $1(1.2)$ & \\
\hline 25-40 years old & $2(8.3)$ & $20(24.7)$ & \\
\hline 41-50 years old & $2(8.3)$ & $21(25.9)$ & \\
\hline $51-60$ years old & $9(37.5)$ & $28(34.6)$ & \\
\hline$>60$ years old & $11(45.8)$ & $11(13.6)$ & \\
\hline Insurance & & & 0.022 \\
\hline None & $0(0.0)$ & $3(3.7)$ & \\
\hline Private & $4(17.4)$ & $37(45.7)$ & \\
\hline Public & $19(82.6)$ & $41(50.6)$ & \\
\hline ART Class a & & & 0.646 \\
\hline INSTI & $14(63.6)$ & $61(78.2)$ & \\
\hline INSTI + NNRTI & $2(9.1)$ & $4(5.1)$ & \\
\hline INSTI + PI & $1(4.5)$ & $5(6.4)$ & \\
\hline & & &
\end{tabular}




\begin{tabular}{|c|c|c|c|}
\hline INSTI + PI + NNRTI & $1(4.5)$ & $1(1.3)$ & \\
\hline NNRTI & $1(4.5)$ & $2(2.6)$ & \\
\hline PI & $3(13.6)$ & $4(5.1)$ & \\
\hline $\mathrm{PI}+\mathrm{EI}^{\mathrm{b}}$ & $0(0.0)$ & $1(1.3)$ & \\
\hline $\begin{array}{l}\text { Years Living With HIV } \\
\text { (mean)(SD) }\end{array}$ & $15.8(8.7)$ & $12.6(9.4)$ & 0.165 \\
\hline HIV Viral Load Range & & & 0.037 \\
\hline$<200($ copies $/ \mathrm{mL})$ & $19(82.6)$ & $74(91.4)$ & \\
\hline $200-1000$ (copies $/ \mathrm{mL})$ & $0(0.0)$ & $1(1.2)$ & \\
\hline$>1000($ copies $/ \mathrm{mL})$ & $0(0.0)$ & $4(4.9)$ & \\
\hline$>5000($ copies $/ \mathrm{mL})$ & $4(17.4)$ & $2(2.5)$ & \\
\hline Mean CD4 Count (SD) & $444.3(243.8)$ & $578.6(254.6)$ & 0.026 \\
\hline CD4 Count $\leq 200$ cells $/ \mathbf{m m} 3$ & $4(17.4)$ & $6(7.4)$ & 0.302 \\
\hline $\begin{array}{l}\text { CD4 Count Nadir Range } \\
\text { (cells/mm3) }\end{array}$ & & & 0.053 \\
\hline$<50$ cells $/ \mathrm{mm} 3$ & $7(29.2)$ & $13(16.0)$ & \\
\hline $51-100$ cells $/ \mathrm{mm} 3$ & $5(20.8)$ & $6(7.4)$ & \\
\hline $101-200$ cells $/ \mathrm{mm} 3$ & $5(20.8)$ & $13(16.0)$ & \\
\hline$>200$ cells $/ \mathrm{mm} 3$ & $3(12.5)$ & $32(39.5)$ & \\
\hline $\begin{array}{l}\text { CD4 Count Nadir } \leq \mathbf{2 0 0} \\
\text { cells/mm3 }\end{array}$ & $17(70.8)$ & $32(39.5)$ & 0.014 \\
\hline AIDS-Defined & $20(87.0)$ & $47(61.0)$ & 0.039 \\
\hline ART Resistance $^{c}$ & $10(50.0)$ & $22(34.9)$ & 0.345 \\
\hline Hepatitis B Infection & & & 0.417 \\
\hline Chronic Hepatitis B Infection & $3(12.5)$ & $5(6.2)$ & \\
\hline Resolved Hepatitis B Infection ${ }^{d}$ & $2(8.3)$ & $13(16.0)$ & \\
\hline Hepatitis C Infection $=$ & & & 0.128 \\
\hline Chronic Hepatitis C Infection & $2(8.3)$ & $2(2.5)$ & \\
\hline Treatment with Cure & $4(16.7)$ & $5(6.2)$ & \\
\hline Spontaneous Clearance & $3(12.5)$ & $6(7.4)$ & \\
\hline \multicolumn{4}{|l|}{ Comorbidities } \\
\hline BMI (mean (SD)) & $30.6(8.2)$ & $31.6(8.1)$ & 0.609 \\
\hline Cardiovascular Disease (\%) & $14(58.3)$ & $8(9.9)$ & $<0.001$ \\
\hline Diabetes (\%) & $10(41.7)$ & $11(13.6)$ & 0.006 \\
\hline Hypertension (\%) & $17(70.8)$ & $36(44.4)$ & 0.041 \\
\hline Dyslipidemia (\%) & $14(58.3)$ & $37(45.7)$ & 0.391 \\
\hline Chronic Kidney Disease (\%) & $10(41.7)$ & $6(7.4)$ & $<0.001$ \\
\hline Chronic Lung Disease (\%) & $7(29.2)$ & $17(21.0)$ & 0.575 \\
\hline Cirrhosis (\%) & $5(20.8)$ & $2(2.5)$ & 0.007 \\
\hline
\end{tabular}

Note: $\mathrm{a}=$ in addition to NRTI backbone (F/TAF in vast majority of patients); $\mathrm{b}=$ entry inhibitor, i.e. maraviroc; $\mathrm{c}=$ defined as clinically significant resistance to ART in one or more drug class; $\mathrm{d}$ $=$ either isolated anti-HBc (with negative HBV DNA) or anti-HBc + anti-HBs

Hospitalized co-infected patients also demonstrated a statistically significant higher proportion of several key comorbid conditions versus their non-hospitalized counterparts including 
cardiovascular disease (58.3\% versus $9.9 \%$ ), diabetes (41.7\% versus $13.6 \%)$, hypertension ( $70.8 \%$ versus $44.4 \%)$, chronic kidney disease $(41.7 \%$ versus $7.4 \%)$ and cirrhosis $(20.8 \%$ versus $2.5 \%$ ). Half of hospitalized patients had known clinically significant ART resistance. Age, BMI $>30 \mathrm{~kg} / \mathrm{m}^{2}$, cardiovascular disease, chronic kidney disease and cirrhosis were independently associated with hospitalization by logistic regression (Table 3 ).

Table 3. Logistic Regression Model of Hospitalization

\begin{tabular}{lrcc}
\hline Variable & $\begin{array}{c}\text { Odds } \\
\text { Ratio }\end{array}$ & $\begin{array}{l}\text { 95\% Confidence } \\
\text { Intervals }\end{array}$ & p-Value \\
\hline Age & 1.12 & {$[1.01 ; 1.23]$} & 0.029 \\
\hline Male sex & 0.15 & {$[0.02 ; 1.38]$} & 0.092 \\
\hline Black race & 0.86 & {$[0.11 ; 6.63]$} & 0.885 \\
\hline BMI $>30$ & 7.36 & {$[0.99 ; 54.79]$} & 0.051 \\
\hline Cardiovascular Disease & 26.30 & {$[2.73 ; 253.53]$} & 0.004 \\
\hline Diabetes & 1.21 & {$[0.16 ; 8.91]$} & 0.854 \\
\hline Hypertension & 0.28 & {$[0.03 ; 2.46]$} & 0.250 \\
\hline Chronic Kidney Disease & 44.96 & {$[2.75 ; 735.55]$} & 0.007 \\
\hline Cirrhosis & 61.36 & {$[1.81 ; 2081.76]$} & 0.022 \\
\hline AIDS-Defined & 0.17 & {$[0.02 ; 1.61]$} & 0.122 \\
\hline INSTI-Based ART & 0.79 & {$[0.11 ; 5.51]$} & 0.808 \\
\hline HIV Viral Load $\leq 200$ & 0.41 & {$[0.02 ; 7.04]$} & 0.541 \\
\hline Private Insurance & $\mathbf{0 . 4 5}$ & {$[\mathbf{0 . 0 5} ; 3.95]$} & $\mathbf{0 . 4 7 2}$ \\
\hline
\end{tabular}

Comparing infection and hospitalization rates across racial and ethnic groups, White co-infected patients were slightly underrepresented when compared to their share of the overall clinic population ( $24.8 \%$ versus $30.2 \%$ clinic population), but significantly underrepresented in terms of the proportion that were hospitalized (16.7\%). Conversely, Black patients were far more likely to be hospitalized as compared to White patients (with $79.2 \%$ of co-infected Black patients being hospitalized), while their overall rate of co-infection remained proportional to their share of the clinic population (62.9\% versus $60 \%$ clinic population).

In addition to the co-morbidities addressed above, we assessed the hepatitis B status of all PLWH infected with SARS-CoV-2. While not statistically significant, a lower rate of hospitalization was seen in individuals with a history of naturally resolved HBV. Amongst those hospitalized, $2 / 24(8.3 \%)$ patients had a history of resolved HBV, compared to 13/81 (16\%) nonhospitalized patients.

\section{Discussion and Public Health Implications}

Our cohort data is the first to capture the experience of PLWH co-infected with SARS-CoV-2 in the State of Delaware, during the first year of the COVID-19 pandemic. In keeping with previously published data, increasing age and the presence of well-defined co-morbidities in the setting of HIV/SARS-CoV-2 co-infection are independently associated with higher odds of hospitalization. ${ }^{1,6,11,17,22}$ Whether HIV itself represents an independent risk factor for severe COVID-19 remains a matter of debate: ${ }^{1,23}$ our study patients' immunologic profiles and HIVspecific histories (including nadir CD4 count, virologic suppression, AIDS-defined status and known ART resistance) were not found to be independently associated with hospitalization. However, from an immunological perspective, we observed that AIDS-defined individuals were 
over-represented amongst PLWH hospitalized with SARS-CoV-2 co-infection, and historical nadir CD4 counts as well as proximal CD4 counts were lower in hospitalized than nonhospitalized SARS-CoV-2 cases. These observations, along with high rates of ART resistance and significant time living with HIV amongst hospitalized patients, altogether buttress the idea that cumulative lifetime immunosuppression and/or HIV viremia, with the expected associated changes in the underlying immunologic profiles of these patients, may be associated with higher rates of progression to severe COVID-19 in PLWH. Recent data further supports this biologically plausible hypothesis. ${ }^{10,22,26}$

Furthermore, our data highlight the seeming risk of underlying chronic inflammation that is either a direct result of HIV itself and/or multi-morbidity. ${ }^{14,16,17,21}$ We hypothesize that this increased, underlying, chronic inflammation amongst hospitalized co-infected patients may contribute to a more severe presentation of COVID-19. Although not reaching statistical significance, we identified high rates of naturally resolved HBV infection amongst nonhospitalized co-infected patients and postulate there may be an underlying immunologic mechanism to this hypothesis-generating observation. ${ }^{24,25}$

Unfortunately, the social determinants of health that so deeply impacted PLWH prior to the COVID-19 pandemic once again affected our clinic population, with a higher percentage of Black patients being hospitalized versus their White counterparts. The observation that the rate of Black patients diagnosed with HIV/SARS-CoV-2 co-infection was similar to that of Black patients in our general clinic population raises concern for decreased testing in this population, especially given there are consistently reported increased rates of SARS-CoV-2 infection amongst other Black communities in the United States. ${ }^{9,10,13,14,26}$ The above observations suggest that Black PLWH in Delaware are testing less frequently for COVID-19 and presenting to care with more severe disease. Sadly, this picture mirrors the national pattern regarding HIV itself, with Black patients presenting later to care and with more advanced HIV disease. ${ }^{27}$

While our descriptive analysis is potentially suggestive of wider trends, our analysis was limited by a small sample size, incomplete historical data for some variables, and wide confidence intervals. While every attempt was made to identify PLWH with SARS-CoV-2 co-infection in our program population, we certainly did not capture every positive test during the study period. It is possible that not all our clinic patients were tagged/recognized in the EMR, consequently preventing us from receiving electronic notification of SARS-CoV-2 infection. There were instances in which patients reported positive SARS-CoV-2 test results that were unable to be confirmed, as well as several cases of presumptive COVID-19 diagnoses with either no testing or negative testing. We also acknowledge that at the start of the pandemic, testing availability was very limited which resulted in the initial testing of only symptomatic cases. Even as access to testing has expanded throughout Delaware, there remain many barriers to testing that disproportionately affect different communities. In summary, the presented confirmed positive SARS-CoV-2 cases represent our best - albeit imperfect - attempt to capture all cases amongst our clinic population. Larger studies are needed to further investigate the roles of long-term immunosuppression and inflammation, burden of comorbidities, and early and late immunologic responses in COVID-19 outcomes amongst PLWH. 
Doi: $10.32481 / \mathrm{djph} .2021 .12 .016$

\section{Acknowledgments}

We give thanks to all our patients for their strength and perseverance throughout these pandemics, as well as to the Holloway Program's entire staff for their ongoing dedication to patient care.

The authors can be contacted at adam.skrzynski@christianacare.org

\section{References}

1. Bertagnolio, S., Thwin, S. S., Silva, R., Ford, N., Baggaley, R., Vitoria, M., ... Diaz, J. (2021, Jul 18-21). Clinical characteristics and prognostic factors in people living with HIV hospitalized with COVID-19: findings from the WHO Global Clinical Platform. $11^{\text {th }}$ IAS Conference on HIV Science; virtual conference.

2. Bhaskaran, K., Rentsch, C. T., MacKenna, B., Schultze, A., Mehrkar, A., Bates, C. J., . . . Goldacre, B. (2021, January). HIV infection and COVID-19 death: A population-based cohort analysis of UK primary care data and linked national death registrations within the OpenSAFELY platform. The Lancet. HIV, 8(1), e24-e32. PubMed https://doi.org/10.1016/S2352-3018(20)30305-2

3. Western Cape Department of Health in collaboration with the National Institute for Communicable Diseases. South Africa. (. (2021). Risk factors for COVID-19 death in a population cohort study from the Western Cape Province, South Africa. Clin Infect Dis, 73(7), e2005-e2015. PubMed

4. Geretti, A. M., Stockdale, A. J., Kelly, S. H., Cevik, M., Collins, S., Waters, L., .. . Semple, M. G. (2020). Outcomes of COVID-19 related hospitalization among people with HIV in the ISARIC WHO Clinical Characterization Protocol (UK): A prospective observational study. Clin Infect Dis. PubMed

5. Gervasoni, C., Meraviglia, P., Riva, A., Giacomelli, A., Oreni, L., Minisci, D., . . Cattaneo, D. (2020). Clinical features and outcomes of HIV patients with coronavirus disease 2019. Clinical Infectious Diseases, 71(16), 2276-2278. PubMed https://doi.org/10.1093/cid/ciaa579

6. Hadi, Y. B., Naqvi, S. F. Z., Kupec, J. T., \& Sarwari, A. R. (2020, November 1). Characteristics and outcomes of COVID-19 in patients with HIV: A multicentre research network study. AIDS (London, England), 34(13), F3-F8. PubMed https://doi.org/10.1097/QAD.0000000000002666

7. Härter, G., Spinner, C. D., Roider, J., Bickel, M., Krznaric, I., Grunwald, S., . . Hoffmann, C. (2020, October). COVID-19 in people living with human immunodeficiency virus: A case series of 33 patients. Infection, 48(5), 681-686. PubMed https://doi.org/10.1007/s15010-020-01438-z

8. Huang, J., Xie, N., Hu, X., Yan, H., Ding, J., Liu, P., . . Wang, X. (2021). Epidemiological, virological and serological features of COVID-19 cases in people living with HIV in Wuhan City: A population-based cohort study. Clin Infect Dis, e2086. PubMed

9. Mascolini, M. (2020, Jul 6-10). COVID-19 rate no higher with HIV in largest US HIV+/HIVCohort. AIDS 2020: 23rd International AIDS Conference Virtual. 
10. Shalev, N., Scherer, M., LaSota, E. D., Antoniou, P., Yin, M. T., Zucker, J., \& Sobieszczyk, M. E. (2020). Clinical characteristics and outcomes in people living with HIV hospitalized for COVID-19. Clinical Infectious Diseases, 71(16), 2294-2297. PubMed https://doi.org/10.1093/cid/ciaa635

11. Sigel, K., Swartz, T., Golden, E., Paranjpe, I., Somani, S., Richter, F., . . Glicksberg, B. S. (2020). Covid-19 and people with HIV infection: Outcomes for hospitalized patients in New York City. Clinical Infectious Diseases, 71(11), 2933-2938. PubMed https://doi.org/10.1093/cid/ciaa880

12. Stoeckle, K., Johnston, C. D., Jannat-Khah, D. P., Williams, S. C., Ellman, T. M., Vogler, M. A., . . Choi, J. J. (2020, August 1). COVID-19 in hospitalized adults with HIV. Open Forum Infectious Diseases, 7(8), ofaa327. PubMed

13. Byrd, K. M., Beckwith, C. G., Garland, J. M., Johnson, J. E., Aung, S., Cu-Uvin, S., . . . Kantor, R. (2020, July). SARS-CoV-2 and HIV coinfection: Clinical experience from Rhode Island, United States. Journal of the International AIDS Society, 23(7), e25573. PubMed https://doi.org/10.1002/jia2.25573

14. Collins, L. F., Moran, C. A., Oliver, N. T., Moanna, A., Lahiri, C. D., Colasanti, J. A., . . . Sheth, A. N. (2020, October 1). Clinical characteristics, comorbidities and outcomes among persons with HIV hospitalized with coronavirus disease 2019 in Atlanta, Georgia. AIDS (London, England), 34(12), 1789-1794. PubMed https://doi.org/10.1097/QAD.0000000000002632

15. Meyerowitz, E. A., Kim, A. Y., Ard, K. L., Basgoz, N., Chu, J. T., Hurtado, R. M., ... Gandhi, R. T. (2020, October 1). Disproportionate burden of coronavirus disease 2019 among racial minorities and those in congregate settings among a large cohort of people with HIV. AIDS (London, England), 34(12), 1781-1787. PubMed https://doi.org/10.1097/QAD.0000000000002607

16. Childs, K., Post, F. A., Norcross, C., Ottaway, Z., Hamlyn, E., Quinn, K., . . Taylor, C. (2020, November 5). Hospitalized patients with COVID-19 and human immunodeficiency virus: A case series. Clin Infect Diss, 71(8), 2021-2022. PubMed

17. Etienne, N., Karmochkine, M., Slama, L., Pavie, J., Batisse, D., Usubillaga, R., . ... (2020). HIV infection and COVID-19: Risk factors for severe disease. AIDS (London, England), 34(12). https://doi.org/10.1097/QAD.0000000000002651

18. Nomah, D. K., Reyes-Uruena, J., Diaz, Y., Moreno, S., Aceiton, J., Bruguera, A., . . Miro, H. M. (2021, Jul 18-21). Unsuppressed plasma HIV-RNA viral load is associated with worse COVID-19 outcomes among people living with HIV. $11^{\text {th }}$ IAS Conference on HIV Science; virtual conference.

19. Dandachi, D., Geiger, G., Montgomery, M. W., Karmen-Tuohhy, S., Golzy, M., Antar, A. A. R., ... Sax, P. E. (2021). Characteristics, comorbidities, and outcomes in a multicenter registry of patients with HIV and coronavirus disease 2019. Clinical Infectious Diseases, 73(7), e1964-e1972. PubMed https://doi.org/10.1093/cid/ciaa1339

20. Maggiolo, F., Zoboli, F., Arosio, M., Valenti, D., Guarneri, D., Sangiorgio, L., ... Callegaro, A. (2021, February). SARS-CoV-2 infection in persons living with HIV: A single 
center prospective cohort. Journal of Medical Virology, 93(2), 1145-1149. PubMed https://doi.org/10.1002/jmv.26352

21. Vizcarra, P., Pérez-Elías, M. J., Quereda, C., Moreno, A., Vivancos, M. J., Dronda, F., \& Casado, J. L., \& the COVID-19 ID Team. (2020, August). Description of COVID-19 in HIV-infected individuals: A single-centre, prospective cohort. The Lancet. HIV, 7(8), e554e564. PubMed

22. Karmen-Tuohy, S., Carlucci, P. M., Zervou, F. N., Zacharioudakis, I. M., Rebick, G., Klein, E., .. Rahimian, J. (2020, September 1). Outcomes among HIV-positive patients hospitalized with COVID-19. J Acquir Immune Defic Syndr, 85(1), 6-10. PubMed https://doi.org/10.1097/QAI.0000000000002423

23. Durstenfeld, M. S., Sun, K., Ma, Y., Rodriguez, F., Secemsky, E. A., Parikh, R. V., \& Hsue, P. Y. (2021). Impact of HIV infection on COVID-19 outcomes among hospitalized adults in the U.S. medRxiv. doi: https://doi.org/10.1101/2021.04.05.21254938

24. Anugwom, C. M., Aby, E. S., \& Debes, J. D. (2021, January 23). inverse association between chronic hepatitis $b$ infection and coronavirus disease 2019 (COVID-19): Immune exhaustion or coincidence? Clin Infect Dis, 72(1), 180-182. PubMed

25. Fajgenbaum, D. C., \& June, C. H. (2020, December 3). Cytokine Storm. The New England Journal of Medicine, 383(23), 2255-2273. PubMed https://doi.org/10.1056/NEJMra2026131

26. Tesoriero, J. M., Swain, C. E., Pierce, J. L., Zamboni, L., Wu, M., Holtgrave, D. R., . . . Rosenberg, E. S. (2021, February 1). COVID-19 outcomes among persons living with or without diagnosed HIV infection in New York State. JAMA Network Open, 4(2), e2037069. PubMed https://doi.org/10.1001/jamanetworkopen.2020.37069

27. Dailey, A. F., Johnson, A. S., \& Wu, B. (2017, February 3). HIV care outcomes among blacks with diagnosed HIV - United States, 2014. (2017, Feb). MMWR. Morbidity and Mortality Weekly Report, 66(4), 97-103. PubMed https://doi.org/10.15585/mmwr.mm6604a2

Copyright (c) 2021 Delaware Academy of Medicine / Delaware Public Health Association.

This is an Open Access article distributed under the terms of the Creative Commons Attribution Non-Commercial License (https://creativecommons.org/licenses/by-nc-nd/4.0/) which permits unrestricted non-commercial use, distribution, and reproduction in any medium, provided the original work is properly cited. 